SEPARATION OF SILVER AND LEAD. By R. BENEDICT and L. GAUS.

THE authors found their process on the different beThe solution containing silver nitrate and lead ni-
The trate-in all about 0.5 gramme of metal-is diluted with cold water in a capacious glass capsule to from $200-300$ c. c.. and solution of potassium iodide more
than sufficient for the complete precipitation of the silver, but not excessive in quantity, is allowed to flow
in. If 0.5 gramme of metal is used, $10 \mathrm{c}$. c. of a $10 \mathrm{per}$
cent. solution of potassium iodide will be sufficient in cent. solution of potassium iodide will be sufficient in any case. We then add $10 \mathrm{c}$. c. of nitric acid free from
chlorine, previously diluted with from 10-20 c. c. of
water. The capsule is then covered with a watch glass and heated on the water bath, when the yellow color and the precipitate chiefly passes at first into orange
of As soon as the liquid has become hot, the lead iodide
red. dissolves, the liquid becomes dark brown, and vapors of iodine are given off. The watch glass is then re
moved and rinsed into the capsule, boiling water
is added, and the capsule is left on the water bath, is added, and the capsule is left on the water bath, less or pale yellow, when the iodine is expelled. The silver iodide is then weighed. The authors collectit in
a small glass tube filled with glass wool, dried at $110^{\circ}$,
and weighed. Wash it first with hot water containing nitric acid and then with a few c. c. of hot water, dry The presence of other metals of the same group, with the exception of mercury, does not interfere. Cuprous odide, bismuth, and cadmium lodide behave with ni-
tric acid like lead iodide; on the other hand, mercu-
rous iodide is converted into red iodide, which is not further attacked.

'The authors publish very favorable results. In the in the same manner. They dissolve in nitric acid, dilute, precipitate with potassium iodide, and heat on For determining silver in impure leads, from 10-50 grammes of the same, according to the proportion of grammes of the same according to the proportion of
silver. is dissolved in dilute nitric acid containing tarsilver. is dissolved in dilute nitric acid containing tar-
taric acid. To 10 grammes of the sample they use 10
c. c. nitric acid free from chlorine, and an equal quantity of a saturated solution of tartaric acid. The pres-
ence of the latter effects much more rapid and com-
plete solution The soiution is heated until the oxidaplete solution. The solution is heated until the oxida-
tion is completed, diluted with boiling water. filtered into a glass capsule, diluted to from $300-500 \mathrm{c}$. c.
allowed to cool, $10 \mathrm{c}$. $\mathrm{c}$. of a 10 per cent. solution of po tassium iodide areadded and it is heated on the water bath. generally sufficient for oxidizing the lead iodide; if the development of iodine vapors and the brown color
do not appear, a little more dilute nitric acid must be The proportion of silver in galena may be determined
in the same manner. It is oxidized with nitric acid with the addition of tartaric acid. It is most convewith the addition of tartaric acid. It is most convetartaric asid, and water, After the oxidation is com-
pleted, the liquid diluted with hot water, filtered, and
well washed with boiling water, the filtrate is allowed well washed with boiling water, the filtrate is allowed
to cool. The process is then completed as above.-
Zeit. Anal. Chemie and Chem. Zeitung; Chem. News.

\section{A VOLATILE SERIES OF METALLIC COMPOUNDS.}

By C. F. Townsend, F.C.S.

THE progress of chemical science is continually

bringing to ligh t new wonders and stitrtlitg paradoxes.
Nothing more remarkable and unexpected lias occurred in the recent history of chemistry than the discovery
of the compounds of nickel and iron with the gas geneof the compounds of nickel and iron with the gas gene-
rally known as carbon monoxide or carbonic oxide.
'The new compounds are called respectively nickel and iron carbonyls, and have evidently a great future before them. Judging from chemical precedent, one
would quite as soon have expected oil and vinegar to form a homogeneous mixture as a combination of the
bodies referred to. In fact, so anomalous did it appear bodies referred to. In fact, so anomalous did it appear
when Mr. Lad wig. Mond first brought the accidentally discovered nickel compound to the notice of the Chemi-
cal Society in the midale of 1890 , that many almost re-
fused to believe in the possibility of its However, there is no doubt about it. Nickel carbony, a considerable quantity of which was exhibited at a conversazione of the Royal Society held in June last,
and also at the meeting of the British Association, is obtained by merely passing carbon monoxide-a product of the incomplete combustion of coke or charcoal,
and which may of ten be seen burning with a lambent blue flame at the top of a clear fire-over the finely divided metal, and condensing the resulting vapor in a
tube surrounded with ice and salt. Its properties have
been very fully investigated both by its discoverers, been very fully investigated both by its discoverers, Messrs. Mond, Langer and Quincke, and also by M.
Berthelot, who published his results in the Comptes Rendus.
It is a liquid of very high refractive power and brilunder which it may be kept. without change, provided the vessel is completely filled and the water contains
no air. It solidifies at $1: 3^{\prime} \mathrm{F}$., and boils at $109^{\circ} \mathrm{F}$., and the vapor, if lighted, burns with a strongly luminous flame, which appears smoky in consequence of the separation of metallic nickel. The liquid is very vola
tile, and if the vapor is suddenly heated, a sharp deto-
nation is caused. A mixture of nickel carbonyl with nation is caused. A mixture of nickel carbonyl with
air takes fire, if brought into contact with a very hot steam over red hot coke, and contains about passing air takes fire, if brought into contact with a very hot cent. of carbonic oxide) for illuminating purposes by
body, and occasionally explodes. A mixture of the means of the Farnehjelm system, in which a comb of
lyry vapor and oxygen may be detonated by simple magnesia is raised to incandescence by a number of (lry vapor and oxygen may be detonated by simple magnesia is raised to incandescence by a number of agitation over mercury, and strong oil of vitriol pro- fine gas jets, Sir H. E. Roscoe and Mr. Scudder noticed when heated to $358^{\circ} \mathbf{F}$., splits up again into its original rods after the water gas had impinged on them for a
constituents, the metal and the gas, and the nickel de- few hours. constituents, the metal and the gas, and the nickel de-
posits itself as a brilliant coating on the sides of the posits itself as a brilliant coating on the sides of the
vessel. Advantage is taken of this circumstance to
apply the carbonyl to nickel plating, and a patent has apply the carbonyl to nickel plating, and a patent has were being conducted in a steel works, the first suppo
been taken out by its discoverers for working it on a sition naturally was that the stain was caused by fine
commercial scale. At the lastmeeting of the British particles of iron present in the atmesphere, but by varying the det
Association. Mr. Ludwig Mond described the various inspection showed that the deposit was of a "coral-
uses to which the discovery might be put, and the loid" structure and must, therefore, have been propossibilities which it opened up. The nickel plating : duced by the gas itself. In order to ascertain whether after being heated to the temperature just mentioned, : forward chemically, the gas was filtered through seve. to nickel carbonyl vapor, and solid articles can be ral tight plugs of cotton wool. No difference what-
similarly formed by passing the vapor through heat- ever was observed, and it was concluded that the gat ed moulds. For this purpose, it is found advanta- contained a very minute quantity of a volatile com can also be deposited on any substance by treating it ous chemical tests, which left very little doubt as to its
with the liquid itself, or better, by nickel carbonyl dis- . identity with iron carbonyl. solved in suitable solvents. These processes possess
reat advantage over electro-plating, as not only metal

Coal gas has also been found to contain iron, derived, no doubt, from the slow action of the 7 or 8 per cent.
of carbon monoxide it contains on the iron of the gile in structure, can be coated with a brilliant film of : mains and gas pipes. This accounts for the hitherto
nickel by its means without the tedium and risk of : unexplained black stain so frequently observed on first covering it with a surface of blacklead. Some steatite and other burners. Compressed coal gas has very beautiful specimens of real flowers, plated with begun to take the place of hydrogen in the production
different metals, principally gold and silver, so as to of lime light, and the stain formed on the lime cylin-
bring out the various parts of their structure, were ex- ders is very noticeable, being, it is almost needless to bring out the various parts of their structure, were ex- ders is very noticeable, being, it is almost

A syringa blossom, for instance, would have its sta- The distovery of this series of compounds is quite a
men and anthers plated with gold, its corrolla with revelation to the netallurgical chenist, and already silver, and the stalk and calyx with copper. Needless explains many mysteries. In the cementation process this new process is practically unlimited, for not only in powdered charcoal, and kept at about the melting hold use. but, if required, to delicate muslins, and dress or other fabrics.
The liquid nickel carbonyl is highly poisonous, and,
if injected subcutaneously, acts very powerfully on the animal systen, producing an immediate and remarka-
bly prolonged fall of temperature. It might, bly prolonged fall of temperature. It might, werhil ss, of administering it in sufficiently small doses, and its intensely poisonous action. The carbon monoxide yme is the active agent in causing this effect, the
the blood of animals killed by it exhibits the same and pearances as that of persolns suffocated by inhaling the particularly dangerous, and in cases of recovery the effects do not wear off for several hours after. Th
red corpuscles of the blood owe their color to plex chemical substance known as hæmoglobin, which acts as the carrier of oxygen. In passing through the
lungs oxygen is taken up, and it is converted into oxy-
hæmoglobin, which, when placed so as to intercept the rays of light in the spectroscope, gives quite different lungs the oxygen is carried to different parts of the by oxygen, thus completing the cycle. Carbonic oxide combines with the hæmoglobin to form carboxy-hæmoglobin, an exceedingly stable substance, which can
only be displaced by oxygen with the greatest difficul-
ty. The consequence is that the blood is unable to perform its functions, and the animal rapidly dies
from suffocation. The absorption spectrum of this last body is remarkably characteristic and quite unpected poisoning by charcoal fumes. The vapor of The extraction of the metal from its ores is anothe
Then in 0.5 per cent. valuable use to which the discovery of this compound
will almost certainly be put. The principal sources of nickel are the copper colored arsenical mineral which for years in the hope of obtaining copper-called liupwas first discovered by Gonstadt in 1751 , and speiss, pots in the manufacture of the bright blue pigment known as smalt, which is largely used by paper stain-
ers. Metallic nickel is obtained from these by heating them with charcoal in a furnace, but the product only exide over the crushed mineral, and by simply heating the resulting nickel carbonyl to $358^{\circ} \mathbf{F}$. chemically pure nickel will be deposited.
All attempts to obtain a similarcompound with other metals for a long time proved unsuccessful. As it seemed improbable that nickel should be the only
metal forming such a compound, the investigators per-
severed with the work, and finally succeeded in volatilizing distinct quantities of iron in a current of carbon monoxide. The issuing gas burned with a yellowish
flame, and if passed througl a heated tube deposited a metallic mirror in the cliss, which answered to all the tests for iron with unusual brilliancy. The quan-
tity produced was, however, very small, and the proweeks to volatilize about thirty grains of iron. Even tained more than 0.2 per cent. of the compound, but

The irou carbonyl thus produced is a pale yellow
viscous linuid, nearly half as heavy again as water. It

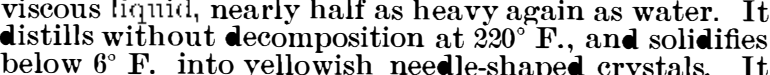
decomposes slowly on exposure to air and, like the
nickel compound, is completely broken up by heating nickel compound, is completely broken up by heating active than its analogue and is not attacked by dilute
oil of vitriol. Its composition was at first thought to be similar to that of nickel carbonyl, but on accurate analysis it was found to contain five proportions of carbon monoxide $\left[\mathrm{Fe}(\mathrm{CO})_{5} \mathrm{j}\right.$ instead of the four which
constitute the latter $\left[\mathrm{Ni}(\mathrm{CO})_{4}\right]$. While engaged in some experiments on the utilizaThis was a serious drawback, as the illuminating as is well known $\left(2,192^{2} \mathbf{F}\right.$.) for eight or ten days. Stee tion of carbon and iron, called carbide of iron, and the principle of all steel making is the same : carbon must iron contains no carbon, it is comparatively soft and
malleable. Wrought iron contains less than 0.3 per malleable. Wrought iron contains less than 0.3 per
cent. of carbon; steel from 0.3 to 1.5 per cent. Above this the metal takes the character of cast iron. The
charcoal which surrounds the bars of iron in the procharcoal which surrounds the bars of iron in the proits pores, which, when heated, forms carbonic oxide.
This gas permeates the iron and gives up its carbon to This gas permeates the iron and gives up its carbon to
the metal, returning again to take up a fresh supply
from the charcoal, and thus acts as a carrier of carbon from the charcoal, and thus acts as a carrier of carbon to and fro in the interstices of the iron, which it gradually converts into almost homogeneous steel, known lar appearance caused by the penetration of the gas. These compounds must play a very important part
too in the blast furnace and in both the Siemens and the Bessemer process, especially the latter. Bessemer ties are burnt out of it by driving a current of air
through the molten metal. When this has been accomplished, a highly carbureted cast iron, called sprie. geleisen, is thrown into the converter in properly re-
gulated quantity, and the carburation of the iron is apidly effected.

Renewed attention has recently been directed to
some volatile compounds of platinum with chlorine and carbon monoxide, which are broken up by water sible way of extricting the metal from its ores. If any discovery of this kind were to facilitate the extraction
of gold, which at its present rate can barely keep up with the demands of the increasing consumption, an
immense boon would be conferred on the civilized orld.-Knowledge.

THE MANUFACTURE OF LIQUORS AND PRESERVES. *

By J. DE BREvans, Chief Chemist of the Municipal

Part II.-Chapter V. (Continued)

SECTION III.-SUPERFINE IIQUUORS. Liqueur surfines.

The quantities of alcohol $\left(85^{\circ}\right)$, sugar, and water usu-

Alcohol $\left(85^{\circ}\right)$

Wugar.. $3 \mathrm{l}$.
$5 \mathrm{k} .500 \mathrm{grm}$.
$2 \mathrm{l} .600 \mathrm{c.c}$.

For 101 .

Cream of Absinthe.

Essence of absinthe.

Essence of anise............

Essence of lemon distilled.

0.6 grm.

Anisette.

Essence of star anise.

Essence of anise ........

Essence of coriander.

Extract of orris.....

$\ldots$

Crême de Barbades.

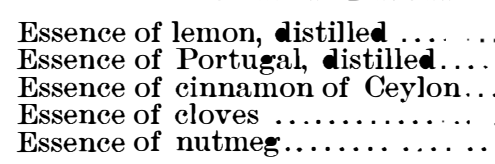

$\begin{array}{ll}3 & \text { grm. } \\ 0.4 & \text { grm. }\end{array}$

$0 \cdot 4 \mathrm{grm}$.

Liqueur de la grande Chartreuse.

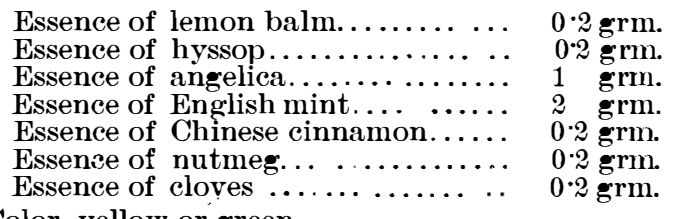

Color, yellow or green.

Curaçao.

$\begin{array}{llrl}\text { Essence of curacao, distilled... . . . . } & 10 & \mathbf{g r m} \\ \text { Essence of Portugal, distilled... } & \text {... } & 4 & \mathrm{grm} .\end{array}$ Bitter infusion of curacao a sufficient quantity; color 